\title{
Catalytic Converter Developed By Washcoat Of Y-Alumina On Nickel Oxide (Nio) Catalyst In FeCrAl Substrate For Exhaust Emission Control: A Review
}

\author{
A.M.Leman ${ }^{1,}{ }^{*}$, J.Afiqah ${ }^{1}$, Fakhrurrazi Rahman ${ }^{1}$, Dafit Feriyanto ${ }^{1}$, Supa'at Zakaria ${ }^{1}$, and \\ R.Rahmad ${ }^{1}$ \\ ${ }^{1}$ Faculty of Engineering Technology, Universiti Tun Hussein Onn Malaysia (UTHM) \\ Parit Raja, Batu Pahat, 86400 Johor, Malaysia.
}

\begin{abstract}
Automobile exhaust emission control is one of the trending issues in automobile research field. The existing catalytic converter using the noble metals of platinum $(\mathrm{Pt})$, palladium $(\mathrm{Pd})$ and rhodium $(\mathrm{Rd})$ recently were in limited supply and higher in cost. There is a need for the automotive industry to produce ultra-low emitting vehicles at a reasonable cost. The objective of this study is to investigate the effectiveness of methods of fabrication of modified catalytic converter by approaching $\mathrm{FeCrAl}$ as a substrate which treated using ultrasonic bath technique to improve the exhaust emission control. The modified catalytic converter preparation will involve the ultrasonic bath process of $\mathrm{FeCrAl}$ foil which has fabricated as metallic monolith coated by $\gamma-\mathrm{Al}_{2} \mathrm{O}_{3}$ powder. Nickel as catalyst material will be prepared using electroplating process. The oxidation test will be conducted using a tube and automatic furnace in temperature of $1100^{\circ} \mathrm{C}$ for 100 hours. Mitsubishi $4 \mathrm{G} 931800 \mathrm{cc}$ Petrol E.F.I with a multi -gas analyzer equipped with a hydraulic dynamometer will be used for emission measurements of $\mathrm{HC}, \mathrm{CO}$, and $\mathrm{NOx}$ in varying speed and load for both conditions with and without catalytic converter. The result will expect the $\gamma-\mathrm{Al}_{2} \mathrm{O}_{3}$ as the washcoat material that fully embedded to $\mathrm{FeCrAl}$ substrate with the combination of ultrasonic and electroplating technique will effectively convert the $\mathrm{CO}$, $\mathrm{NOx}$ and $\mathrm{HC}$ to $\mathrm{CO}_{2}, \mathrm{NO}_{2}$ and $\mathrm{H}_{2} \mathrm{O}$ which means that catalytic converter is effective to improve exhaust emission control of diesel engine. The $\mathrm{FeCrAl}$ substrate as a metallic catalytic converter which coated by $\gamma-\mathrm{Al}_{2} \mathrm{O}_{3}$ using ultrasonic and nickelelectroplating technique may improve the exhaust emission control.
\end{abstract}

\section{Introduction}

Recent haze crisis was among the most terrific impact resulting from a critical level of urban air pollution in Malaysia. Exhaust emission from automobile has become the largest source that contributes to air pollution. Each automobile could release nearly 200 different components in its exhaust gases into the atmosphere [1]. In recent years, many researchers

\footnotetext{
*Corresponding author: mutalib@uthm.edu.my
} 
indicate that exposure levels have increased gradually worldwide, especially in rapidly large populations of industrializing countries [2]. The vehicle population can be estimated to grow close to 1300 million by the year 2030 [3].

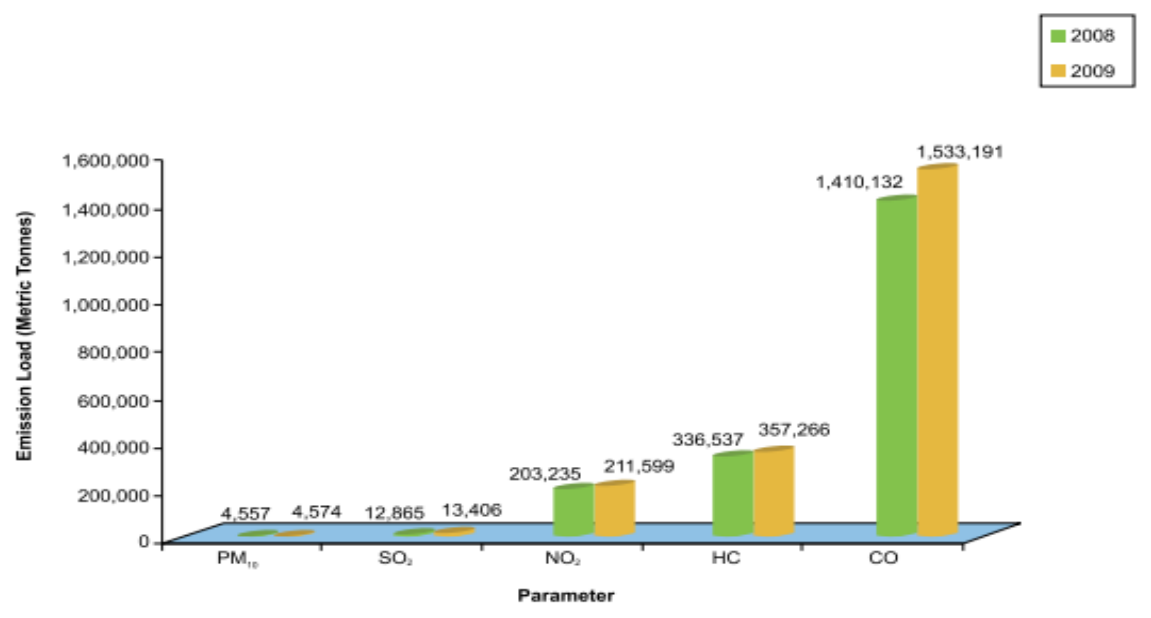

Fig. 1. Air Pollutant Emission Load from Motor Vehicles in 2008-2009 [4].

At the normal engine operating conditions, the typical exhaust gas composition are: carbon monoxide (CO, 0.5 vol.\%), unburned hydrocarbons (HC, $350 \mathrm{ppm})$, nitrogen oxides (NOx, $900 \mathrm{ppm})$ hydrogen $\left(\mathrm{H}_{2}, 0.17\right.$ vol.\%), water $\left(\mathrm{H}_{2} \mathrm{O}, 10\right.$ vol.\%), carbon dioxide $\left(\mathrm{CO}_{2}\right.$, 10 vol. \%), oxygen $\left(\mathrm{O}_{2}, 0.5\right.$ vol. \%) [5].

The catalytic converter is a tool built-in into the exhaust system of an automobile that functioning to cut down the amount of $\mathrm{CO}$, NOx and unreacted $\mathrm{HC}$ in automotive emissions [6]. This catalytic converter is mounted along the exhaust pipe of the engine and has a porous ceramic structure through which the exhaust gas flows into the container [7]. Out of various existing technologies for the control of vehicle exhaust emission, catalytic converter has been found to be the best option. These gases are eliminated by the basic reactions occur inside a catalytic converter through oxidation for $\mathrm{CO}$ and $\mathrm{HC}$ and reduction for NOx.

Most of the catalytic converter used today consists of a monolithic structure which is ceramic honeycomb or metallic matrix. Monolith is known as multichannel which the exhaust gas flow with a high volume flow rate [8]. The schematic conversion of Three Way Catalyst (TWC) in Figure 2 shows the simultaneous reaction of oxidation and reduction in TWC in which the most common type of catalytic converter used $[9,10]$.

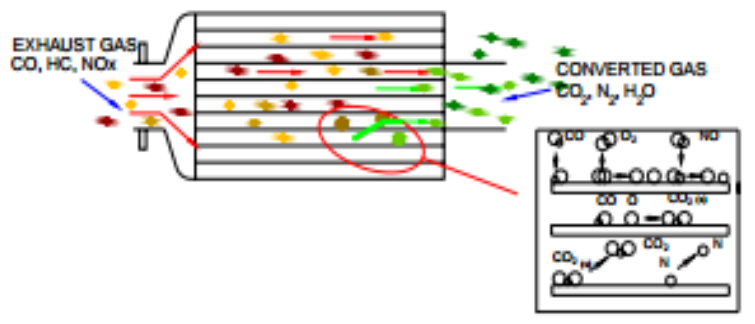

Fig. 2. Schematic of a three way catalyst converter [11]. 
The existing of excellent oxidation catalyst materials was usually based on the precious metal (Pt, $\mathrm{Pd}$, and $\mathrm{Rd})$. However, those materials are expensive and limited supply [12, 13]. In response to this matter, many researchers investigate an alternative catalyst such as the cheaper ranges of oxides (e.g. $\mathrm{CuO}, \mathrm{V}_{2} \mathrm{O}_{5}, \mathrm{NiO}, \mathrm{MoO}_{3}$, and $\mathrm{Cr}_{2} \mathrm{O}_{3}$ ) to replace the use of precious metal [14].

\section{Non-Noble Catalyst Development}

The development of catalytic converter has evolved over the last three decades since the introduction of the first catalyst on diesel cars. There were many research works were made to investigate the best material for the replacement of the noble metals. These noble metals also could contribute to converter meltdown, carbon deposit, catalyst fracture and also poisoning in some cases [15].

The latest studies of catalyst performance were done by Ranganathan et al. [16]. They have studied the performance of two types converters which are the metal oxide such as titanium dioxide $\left(\mathrm{TiO}_{2}\right)$, cerium oxide $\left(\mathrm{CeO}_{2}\right)$ and copper nitrate $\left(\mathrm{Cu}\left(\mathrm{NO}_{3}\right)_{2}\right)$, Zirconium dioxide $\left(\mathrm{ZiO}_{2}\right)$ with wire mesh substrate. Both the catalyst material used in this is inexpensive in comparison with conventional catalyst such as noble metals like Platinum $(\mathrm{Pt})$, Palladium $(\mathrm{Pd})$ and Rhodium $(\mathrm{Rh})$. The study shows a positive result that is the new two catalyst catalytic converters are effective than the present Original Engine Manufacture catalytic converter. The emission from exhaust is rectified up to $20 \%$ than the OEM fitted values.

Studies by Irawan et al. [17] have investigated the new optimum design of ManganeseCoated Copper catalytic converter. Catalytic Converter design and modification of catalytic materials can be an alternative to overcome the high air pollution problem from the transportation sector, especially particular $\mathrm{CO}$ exhaust emissions from gasoline motors. The result shows the increases of catalyst amount cells decreased the concentration of carbon monoxide exhaust emission. The limitation of this study is that they have only focused to reduced exhaust emission of carbon monoxide in order to find the optimum design of the catalytic converter.

The use of different catalyst of copper oxide $(\mathrm{CuO})$, cerium oxide $\left(\mathrm{CrO}_{2}\right)$ and zirconium dioxide $\left(\mathrm{ZrO}_{2}\right)$ was presented by Walke et al. [18]. The purpose of this study is to determine the emission characteristics of a compression ignition engine. The result showed that all the three catalyst reduce the $\mathrm{CO}$ emission. The catalyst (zirconium dioxide + cerium oxide), reduce NOx emission. However, the brake thermal efficiency decreases with the use of all catalyst in the pollutant conversion.

A study on the development and performance analysis of nickel-based catalytic converter was conducted by Narendrasinh et al. [19]. This study introduces a non-noble (nickel) based catalytic converter to reduce diesel engine exhaust emission. The nickel was used as the oxidizing agents and stainless steel as a substrate. The result shows that nickel works in a limited proportion as a catalyst for the conversion of pollutants. Nickel has reduced $\mathrm{HC}$ by $40 \%$ while $\mathrm{CO}$ by $35 \%$. Thus, this study introduce the use of new catalyst of nickel oxide $(\mathrm{NiO})$ to full washcoat material on the catalyst and substrate using electrochemical and modified surface treatment via ultrasonic bath technique. It purposed to improve the exhaust emission control system. $\mathrm{NiO}$ created through plating $\mathrm{Ni}$ to the substrate $\mathrm{FeCrAl}$ and $\mathrm{NiO}$ existed through oxidization in high temperature. This approach is completely creatively new in order to replace the existing of excellent catalyst materials of precious metal of $\mathrm{Pt}, \mathrm{Pd}$, and $\mathrm{Rd}$. 


\section{Methods and Materials}

\subsection{Preparation of Modified Catalytic Converter}

There are several methods for coating the fabrication of modified catalytic converter such as ultrasonic bath and electroplating technique. Ultrasonic bath is conducted to $\mathrm{FeCrAl}$ foil which have fabricated as metallic monolith coated by $\gamma-\mathrm{Al}_{2} \mathrm{O}_{3}$ powder [20]. The samples are cleaned in water and then proceed in methanol for 5 minutes. During the ultrasonic process, the frequency of $35 \mathrm{kHz}$ and ultrasonic times of 4.5 hours are imposed. That holding time is selected according to Leman et al. [21] that the ultrasonic time for 4.5 hours has most effective to achieve high thermal stability of the metallic material.

The samples are immersed into the beaker with $\gamma-\mathrm{Al}_{2} \mathrm{O}_{3}$ powder and ethanol with the concentration of $20 \mathrm{~g} / \mathrm{l}$. Nickel electroplating process is conducted according to Putrasar et al. [22] for depositing nickel onto FeCrAl. Electroplating is conducted on FeCrAl after new ultrasonic treatment. The electroplating process is conducted through some components such as electrolyte, anti-pitting agent, anode and cathode. The schematic diagram of the electroplating process is shown in Figure 3. Sulphamate type is used as the electrolyte medium. The electrolyte prepared with distilled water, at a constant temperature of 40 $60^{\circ} \mathrm{C}$, and $\mathrm{pH}$ value of solution adjusted to 2.5-4.5 using $\mathrm{HCl}$ and $\mathrm{NaOH}$ reagent. The electrolyte agitated using a magnetic stirrer.

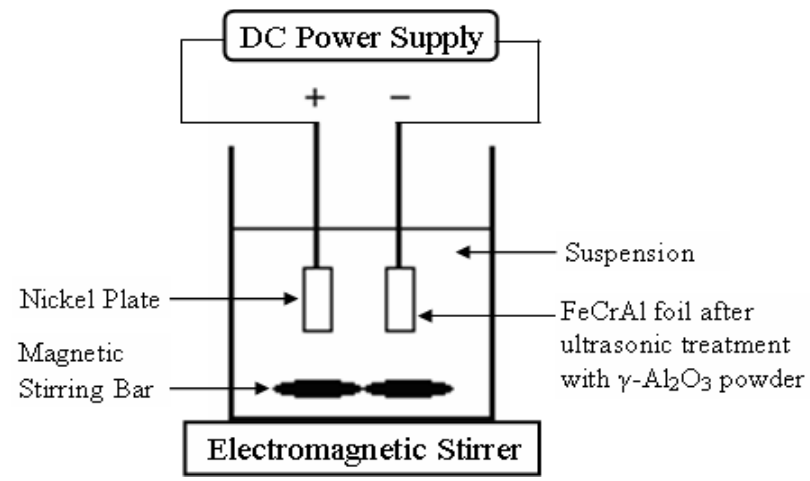

Fig. 3. Schematic diagram of electroplating process.

The oxidation test of coated FeCrAl is conducted according to Badini and Laurella [23], to identify the characteristics of alumina scales grown on a FeCrAl alloy. The cyclic oxidation test is conducted using tube furnace and automatic furnace in temperature of $1100^{\circ} \mathrm{C}$. The test was carried out for 100 hours which divided into 5 cycles [22]. The oxidation cycle were illustrated in Figure 4. The holding time for each cycle was 20 hours for each cycle with the heating and cooling rate of $5^{\circ} \mathrm{C} /$ minutes. 


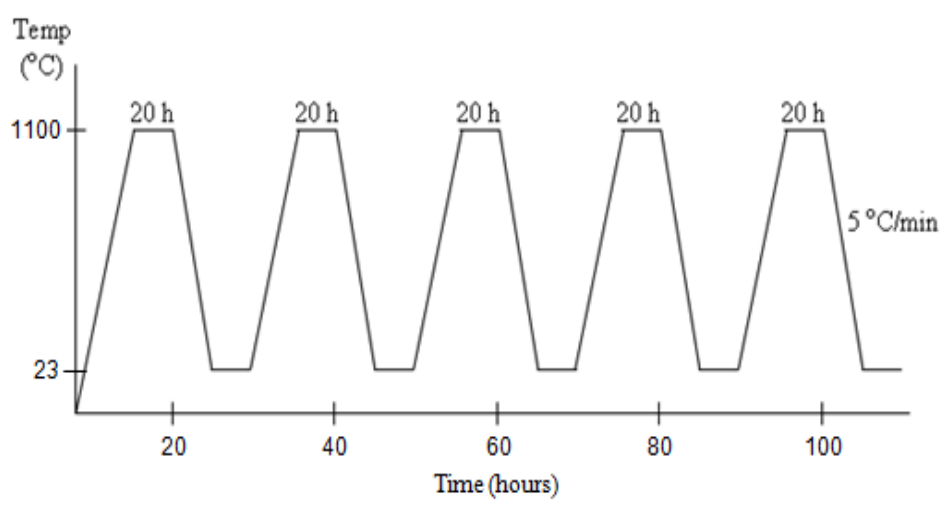

Fig. 4. Cyclic oxidation of coated $\mathrm{Fe}-\mathrm{Cr}-\mathrm{Al}$ at temperature of $1100^{\circ} \mathrm{C}$ for 100 hours [23].

\subsection{Exhaust Emission Testing}

Testing for the effectiveness of the prepared catalyst can be observed by undergo the emission testing. The exhaust gas emission was measured by using multi-gas analyzer equipped with a hydraulic dynamometer for emission measurements of $\mathrm{HC}, \mathrm{CO}$, and NOx shown in Figure 7 [24]. According to the experimental studies by Merkisz [25] the function of gas analyzer is to allowed simultaneous measurement of the mass intensity of exhaust of harmful pollutant concentration. The emission test will be conducted at each operating point in varying speed and load for both conditions with and without a catalytic converter. An experimental study by Alves et al. [26] observed that dynamometer gives an accurate reading of the engine's power, speed, torque, exhaust temperature, etc during the emission testing. A probe was used to measure the gases at the inlet and outlet region, along with the thermocouple, to attain temperature values for ambient and the exhaust gas itself.

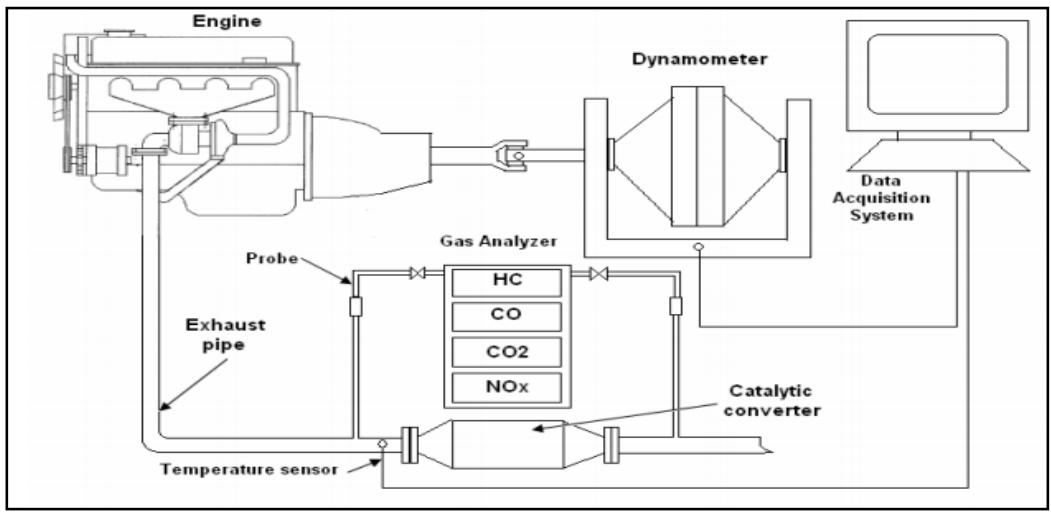

Fig. 7. Emissions measureme nts set-up [25].

\section{Experimental Results}

The aim of the experiment is to reduce the exhaust emission from the effectiveness of fabrication method of modified catalytic converter by approaching $\mathrm{FeCrAl}$ as a substrate which treated using ultrasonic bath technique. According to the emission testing that was conducted by Mizanuzzaman et al. [27], the carbon monoxide (CO2) level emitted from the 
engine without catalytic converter is above $7 \mathrm{ppm}$. The level is decreasing which is lower than $7 \mathrm{ppm}$ when catalytic converter is applied to the vehicles. Kretzschmar [28] found that the emission of the carbon monoxide (CO) during the cold start are higher than the normal operation of vehicles which is 5 to 40 times higher.

\section{Conclusion}

The FeCrAl substrate as a metallic catalytic converter which coated by $\gamma-\mathrm{Al}_{2} \mathrm{O}_{3}$ using ultrasonic and nickel-electroplating technique may improve the exhaust emission control which tested using Mitsubishi 4G93 1800cc Petrol E.F.I. It will become new contribution to the automobile research field.

This work was financially supported by Ministry of Education through FRGS Vot 1612 and ORICC, Universiti Tun Hussein Onn Malaysia (UTHM) for the management of the research grant and Centre for Graduate Studies - UTHM.

\section{References}

1. I.V. Mishakov, A.A. Vedyagin, A.M. Volodin, M.S. Myakisheva, Chemistry for Sustainable Development, 19, 91 (2011)

2. WHO, World Health Organization Fact sheet N313. Air Quality and Health. http://www.who.int/mediacentre/factsheets/fs313/ en/index.html (2013).

3. M.N. Rao and H.V.N Rao. Air pollution (Tata McGraw-Hill publishing company limited, New Delhi, 2003).

4. Department of Environment, Malaysia Environmental Quality Report (Ministry of Natural Resources and Environment, Putrajaya, 2009).

5. S. Pate Bharat, D. Patel Kuldeep, International Journal of Applied Engineering Research, 7, 0973 (2012)

6. D. Sebayang, S.H. Amirnordin, P. Untoro, H. Abd Rahman, Malaysian Technical University Colleges Annual Conference on Engineering and Technology (MUCET), (Malaysia, 2006)

7. V. Ganesan, Internal Combustion Engines. Second Edition (McGraw Hill, 2004)

8. M. Mansha, E.M. Shahid, A.H. Qureshi, Pakistan Journal of Engineering and Applied Sciences, 11, 114 (2012)

9. D. Sebayang, P. Untoro, S.H. Aminordin, H. Abd Rahman, World Engineering Congress (Institute of Engineers Malaysia (IEM), Malaysia, 2007)

10. R.M. Heck, R.J. Farrauto, S.T. Gulati, Catalytic Air Pollution Control Commercial Technology. 3rd edition (John Wiley \& Sons, Inc., USA, 2009)

11. J.C. Prince, C. Treviño, M. Díaz, Proceedings of the World Congress on Engineering (International Association of Engineers, London, 2008)

12. G.C. Koltsakis, A.M. Stamatelos, Prog. Energy Combust. Sci., 23, 1 (1997)

13. M. Benson, C.R. Bennett, J.E. Harry, M.K. Patel, M. Cross, Resour Conserv Recy. 31, 1 (2000)

14. S. Kolaczkowski, Structured Catalysts and Reactors 2nd edition (CRC Press, Taylor \& Francis Group, 2006)

15. A. Chirag and P.R. Pravin, International Journal of Advanced Engineering Research and Studies, 1, 118 (2015)

16. M. Ranganathan, S.A. Renald Remo, U. Kishore, S. Yuvaraj, S. Arun, International Conference on Advance Research and Innovation in Engineering, Science, Technology and Management (ARS College of Engineering, Maraimalai Nagar, Chennai, 2015) 
17. R.M. Bagus Irawan, P. Purwanto, H. Hadiyanto, Procedia Environ Sci. 23, 86 (2014)

18. P.V. Walke, N.V. Deshpande and A.K. Mahalle, Proceedings of the World Congress on Engineering (International Association of Engineers, 2008)

19. R. Narendrasinh Makwana, M. Chirag Amin, K. Shyam, International Journal of Advanced Engineering Technology, 4, 10 (2013)

20. F. Ade, D. Sebayang, P. Yanuandri, S.B. Hasan, A. Bin Otman, P. Untoro, Adv. Mat. Res., 181, 501 (2012)

21. A.M. Leman, D. Feriyanto, M.N.M. Salleh, I. Baba, AMM, 815, 193 (2015).

22. Y. Putrasari, P. Untoro, H. Naili, S. Hasan, D. Sebayang, MEV, 1, 53 (2012).

23. C. Badini, F. Laurella, Surf. Coat. Technol., 135, 291 (2001)

24. A.K.M. Mohiuddin, M. Nurhafez, International Journal of Mechanical and Materials Engineering (IJMME), 2, 1 (2007)

25. J. Merkisz, J. KONES., 18, 253 (2001).

26. C.A. Alves, A.I. Calvo, D.J. Lopes, T. Nunes, A. Charron, M. Goriaux, P. Tassel, P. Perret, International Scholarly and Scientific Research \& Innovation, 7 (2013)

27. M.D. Mizanuzzama, Amitava Ghosh Dastidar, Mohammad Rajib Uddin Rony, Reasat Azam, M.D. Almostasim Mahmud, Int. J. Eng. Res. Appl., 3, 313 (2013)

28. J.G. Kretzschmar, Air Quality, 9 (1997) 